\title{
Agrobacterium-mediated Genetic Transformation in Lentil (Lens culinaris Medik.) followed by In vitro Flowering and Seed Formation
}

\author{
Subroto K. Das, Kishwar Jahan Shethi, M. I. Hoque \\ and R. H. Sarker* \\ Plant Breeding and Biotechnology Laboratory, Department of Botany, University of \\ Dhaka, Dhaka-1000, Bangladesh
}

Key words: Lentil, Lens culinaris, Transformation, In vitro flowering, Seed formation

\begin{abstract}
Genetic transformation system was developed for two microsperma varieties of lentil (Lens culinaris Medik.), namely Bari Masur-4 (BM-4) and Bari Masur-5 (BM5) using Agrobacterium tumefaciens strain LBA4404 harbouring binary plasmid pBI121, containing GUS and nptII genes. Three different types of embryo explants, namely cotyledonary node $(\mathrm{CN})$, decapitated embryo (DE) and cotyledone attached decapitated embryo (CADE) were used. Highest GUS positive expression was found in DE followed by CADE as detected by transient assays. Following Agrobacterium infection CADE showed better response in developing multiple shoots on MS supplemented with $2.22 \mu \mathrm{M}$ BAP, $2.32 \mu \mathrm{M}$ $\mathrm{Kn}, 0.29 \mu \mathrm{M} \mathrm{GA} 3$ and $30.35 \mu \mathrm{M}$ tyrosine. Selection of the transformed shoots was carried out by gradually increasing the concentration of kanamycin up to 200 $\mathrm{mg} / \mathrm{l}$. Transgenic lentil shoots were produced with an overall frequency of $1.009 \%$. In vitro rooting appeared to have a limitation in obtaining complete plantlets in lentil, therefore in vitro flowering and seed formation were induced in transformed shoots of lentil with a view to recovering of the transgenic progenies. GUS positive shoots were found to produce in vitro flowers and pods on half-strength MS containing 98.4 $\mu \mathrm{M}$ IBA and 2.69 $\mu \mathrm{M}$ NAA. Expression of gene was detected in various tissues of the transformed shoots. Stable integration of GUS gene was also confirmed through PCR analysis.
\end{abstract}

\section{Introduction}

Lentil (Lens culinaris Medik.) is widely cultivated in the Middle East, West Asia, North Africa and Indian subcontinent. It ranks the sixth most important pulse crop of the world (Neelam et al. 1988). Lentil (locally known as "Masur") has been regarded as the most popular pulse crop in Bangladesh and ranks first in

*Author for correspondence: <rhsarker2000@yahoo.co.uk>. 
terms of consumption and total area in which different varieties are cultivated (Gowda and Kaul 1982). The total area under lentil cultivation in Bangladesh during 2009 - 2010 was 191000 acres with an average production of 72000 MT (BBS 2009 - 2010).

Lentil seeds are very nutritious having protein levels ranging $20-36 \%$ (Gulati et al. 2002). In addition to its nutritive value, like other legume species, it has the ability to fix atmospheric nitrogen (Duranti and Gius 1997). However, lentil is typically characterized by low yield potential. Several factors are believed to be responsible for the lower production of this important crop which include its susceptibility to pest and diseases, massive flower drop as well as post harvest loss. Conventional breeding methods including hybridization technique and selection are being carried out to develop improved varieties in a wide range of crops. However, in lentil the progress of such improvement is hampered due to the inadequate genetic variability caused by a predominantly high degree of self-pollination. Moreover, crossing in microsperma lentil is tedious because of its small size of flowers.

It is therefore, imperative to look for some other methods to induce genetic variability in lentil. Genetic transformation can supplement traditional crop improvement procedures and this approach can be used in introducing desired traits which is not possible through conventional breeding alone (Gardner 1993). Thus it might be possible that, genetic transformation combined with traditional breeding techniques, could aid in improving both the quality and yield of lentil.

To date limited information is available on lentil genetic transformation using Agrobacterium tumefaciens (Warkentin and McHughen 1991, 1992, 1993, Larquin et al. 1998, Celikkol et al. 2009, Akcay et al. 2009). A few reports are also available on the in vitro regeneration of plants in lentil. These reports include the regeneration of plants using various explants of lentil such as shoot apics (Bajaj and Dhanju 1979, Singh and Raghuvanshi 1989), nodal explants (Polanco et al. 1988, Ahmad et al. 1997), intact seedlings (Malik and Saxena 1992), cotyledonary nodes (Warkentin and McHughen 1993, Gulati et al. 2001) and cotyledones (Tavallaie et al. 2011).

Recently limited progress has been made both on in vitro regeneration and transformation of microsperma lentil varieties of BM-1, BM-2, BM-3 and BM-4 cultivated in Bangladesh (Sarker et al. 2003a,b, Hassan et al. 2007). It has been possible to transfer marker gene into local microsperma lentil varieties but the recovery of transgenic plant is limited due to lack of effective in vitro root system (Sarker et al. 2003b, Khanam et al. 1995). Under these circumstances, in vitro flowering and development of in vitro fertile seeds have been considered as one of the alternatives in obtaining transformed progenies of lentil. There are a 
number of reports available on in vitro flowering in a variety of plants including citrus (Moss 1969), cauliflower (Vandana et al. 1995), maize (Mandal et al. 2000) and bamboo (Nadgauda et al. 1990, Singh et al. 2000) as well as in vitro fruit development in tomato (Sheeja and Mandal 2003).

The main objective of this study was to develop a protocol for Agrobacteriummediated genetic transformation for local microsperma varieties of lentil for their improvement. Moreover, attempts were also made to recover transgenic plantlets of lentil through in vitro flowering and seed formation.

\section{Materials and Methods}

Two microsperma varieties of lentil (Lens culinaris Medik.), namely Bari Masur-4 (BM-4) and Bari Masur-5 (BM-5) cultivated in Bangladesh were used as plant materials for this investigation. Seeds of these two varieties of lentil were collected from Bangladesh Agricultural Research Institute (BARI), Joydebpur, Gazipur and maintained in the Plant Breeding and Biotechnology Laboratory of the Department of Botany, University of Dhaka. Three different types of embryo explants, namely cotyledonary node $(\mathrm{CN})$, cotyledon attached decapitated embryo (CADE), and decapitated embryo (DE) were used for the development of in vitro shoots. For seed germination, the seeds were first washed in $70 \%$ ethanol $(\mathrm{v} / \mathrm{v})$ for $1 \mathrm{~min}$, and then surface sterilized with $0.1 \% \mathrm{HgCl}_{2}(\mathrm{w} / \mathrm{v})$ solution for 15 min. Seeds were then washed three or four times with sterilized distilled water. The surface sterilized seeds were then cultured on $0.8 \%(w / v)$ water agar medium or cotton bed for germination.

$\mathrm{CN}$ explants were prepared by removing the root and shoot tip as well as half of the cotyledon from three-day-old germinated seeds. CADE and DE explants were prepared from overnight soaked sterilized seeds by splitting them open and removing the root and shoot tips from each embryo.

All the three types of explants, CN, CADE and DE were cultured on multiple shoot regeneration medium containing MS salts supplemented with $2.22 \mu \mathrm{M}$ BAP, $2.32 \mu \mathrm{M} \mathrm{Kn}, 0.29 \mu \mathrm{M} \mathrm{GA}, 30.35 \mu \mathrm{M}$ tyrosine and $3 \%$ sucrose $(\mathrm{w} / \mathrm{v})$ in 250 $\mathrm{ml}$ Erlenmeyer flask containing $60 \mathrm{ml}$ of medium (Sarker et al. 2003b). The $\mathrm{pH}$ of the medium was adjusted to 5.8 with $1 \mathrm{M} \mathrm{NaOH}$ prior to adding $0.8 \%$ agar $(\mathrm{w} / \mathrm{v})$, and autoclaved at $121^{\circ} \mathrm{C}$ for $20 \mathrm{~min}$. The culture vessels were incubated in the growth room under $16 / 8 \mathrm{~h}$ light/dark cycle at $25 \pm 2^{\circ} \mathrm{C}$.

Agrobacterium tumifaciens strain LBA4404 with the binary plasmid pBI121 was used for transformation experiments. The binary vector pBI121 has the background of pBIN19. It contains a scoreable reporter gene GUS ( $\beta$ glucuronidase) driven by a CaMV35S promoter and NOS terminator and a selectable marker gene nptII fused between NOS promoter and NOS terminator 
encoding for the enzyme neomycin phosphotransferase conferring kanamycin resistance (Herrera-Estrella et al. 1983). Fifty $\mathrm{ml}$ of liquid YMB (Hooykaas 1988) containing $50 \mathrm{mg} / \mathrm{l}$ kanamycin was inoculated with Agrobacterium from a fresh bacterial plate and grown at $180 \mathrm{rpm}$ on a rotary shaker at $28^{\circ} \mathrm{C}$ for $16 \mathrm{hr}$.

The overnight grown Agrobacterium culture was centrifuged for $10 \mathrm{~min}$ at $5000 \mathrm{rpm}$ and the pellet was resuspended in liquid MS medium ( $\mathrm{pH}$ 5.8) to make the Agrobacterium suspension. This Agrobacterium suspension was used for infection of explants. Prior to this "Optical Density" (OD) of the bacterial suspension was determined at $600 \mathrm{~nm}$ with the help of a spectrophotometer (Shimadzu, Japan). In obtaining sufficient infection, cut explants were dipped in bacterial suspension for different incubation periods before transferring them to cocultivation medium (MS supplemented with $2.22 \mu \mathrm{M}$ BAP, $2.32 \mu \mathrm{M}$ Kn, $0.29 \mu \mathrm{M}$ $\mathrm{GA}_{3}, 30.35 \mu \mathrm{M}$ tyrosine).

Following infection and incubation, the explants were soaked in sterile Whatman filter papers for $2-3 \mathrm{~min}$ to remove the excess bacterial suspension. All the explants were maintained in co-culture medium for 2 - 4 days in dark condition at $25 \pm 2^{\circ} \mathrm{C}$.

Following co-culture, the explants were washed with distilled water for three or four times until no opaque suspension was seen, then washed for $15 \mathrm{~min}$ with distilled water containing $300 \mathrm{mg} / \mathrm{l}$ ticarcillin (Duchefa, The Netharlands). Then explants were dried with a sterile Whatman filter paper and transferred to shoot regeneration medium with $100 \mathrm{mg} / \mathrm{l}$ ticarcillin. After 7 - 10 days, the regenerated shoots were subcultured in selection medium containing $50 \mathrm{mg} / \mathrm{l}$ kanamycin and $100 \mathrm{mg} / \mathrm{l}$ ticarcillin. Cultures were subcultured regularly at an interval of 12 - 15 days and the concentration of kanamycin was gradually increased up to $200 \mathrm{mg} / \mathrm{l}$ on the selection medium. Shoots survived on selection medium were transferred to half-strength MS containing 98.4 $\mu \mathrm{M}$ IBA and 2.69 $\mu \mathrm{M}$ NAA with $50 \mathrm{mg} / \mathrm{l}$ kanamycin for in vitro flowering and seed formation.

Transformation ability of the explants was monitored by GUS histochemical assay (Jefferson 1987, Gould and Smith 1989) by observing an insoluble indigo blue colour at the site of GUS enzyme activity. Thus, it allows transformed tissues to be screened histochemically. Tissues and shoots under selection pressure of around two months were monitored for stable GUS expression.

Stable integration of GUS gene in the lentil genomic DNA was analysed by PCR. For this purpose DNA was isolated from transformants as well as nontransformed shoots using the CTAB method (Doyle and Doyle 1990). For the detection of the GUS coding sequence, DNA was subjected to PCR using the following primers and conditions: forward 5'-CCT GTA GAA ACC CCA ACC CG-3' and reverse 5'-TGG CTG TGA CGC ACA GTT CA-3' (MGW-Biotech, AG, 
and Germany). All primers were used at a concentration of $100 \mathrm{pmol} / \mu \mathrm{l}$. The plasmid pBI121 isolated from Agrobacterium tumefaciens was used as the positive control. PCR reaction mix of $25 \mu \mathrm{l}$ contained $2.5 \mu \mathrm{l}$ of $10 \times$ PCR buffer with 15 $\mathrm{mM} \mathrm{MgCl} 2$ (Gene Craft, Germany), $1 \mu \mathrm{l}$ of $5 \mathrm{mM}$ of the dNTP mix, $1 \mu \mathrm{l}$ of Red Taq polymerase (Natutech, Germany), $1 \mu \mathrm{l}$ of each of the respective primers, and $1 \mu \mathrm{l}(50-80 \mathrm{ng} / \mu \mathrm{l})$ of the sample DNA and $17.5 \mu \mathrm{l}$ ultra pure water. For PCR amplification of the GUS gene, DNA was denatured at $94^{\circ} \mathrm{C}$ for $3 \mathrm{~min}$ and then amplified in 30 cycles using $94^{\circ} \mathrm{C}$ for $1 \mathrm{~min}, 64^{\circ} \mathrm{C}$ for $1 \mathrm{~min}$ (annealing) and $72^{\circ} \mathrm{C}$ for $1 \mathrm{~min}$ followed by $5 \mathrm{~min}$ at $72^{\circ} \mathrm{C}$. For $n p t I I$ gene the cycling conditions were 3 min at $94^{\circ} \mathrm{C}$ denaturtion and 30 amplification cycles using $94^{\circ} \mathrm{C}$ for $1 \mathrm{~min}, 55^{\circ} \mathrm{C}$ for $1 \mathrm{~min}$ (annealing) and $72^{\circ} \mathrm{C}$ for $1 \mathrm{~min}$ followed by $5 \mathrm{~min}$ at $72^{\circ} \mathrm{C}$. The amplified DNA was run on $1.0 \%$ agarose gel and stained with ethidium bromide $(0.05 \mu \mathrm{g} / \mathrm{ml})$.

\section{Results and Discussion}

The present investigation was undertaken to establish an efficient transformation protocol for microsperma lentil (Lens culinaris Medik.) varieties through Agrobacterium-mediated genetic transformation. Among the different approaches, Agrobacterium-mediated genetic transformation has been considered as the most common and successful method used in various leguminous crop plants including soybean (Hinchee et al. 1988, Meurer et al. 1998), chickpea (Fontana et al. 1993, Kar et al. 1996), and peanut (McKently et al. 1995).

Transformation capability of various explants, namely cotyledonary node $(\mathrm{CN})$, decapited embryo (DE), and cotyledon attached decapited embryo (CADE) of BM-4 and BM-5 variety of lentil was tested using Agrobacterium strains LBA4404 harboring the binary plasmid pBI121 conferring $\beta$-glucuronidase (GUS) and nptII gene. Among all the explants, DE showed the best response towards transformation and in this case the percentage of GUS positive explants for BM-4 and BM-5 were 86.9 and 83.33 , respectively (Table 1). The transforming ability of CADE was found to be the next to that of DE. The percentage of GUS positive explants for BM-4 and BM-5 was 73.6 and 71.6 in case of CADE. Among the three explants $\mathrm{CN}$ showed the lowest transformation ability. Although transformation efficiency was comparatively low for $\mathrm{CN}$ explants but regeneration capacity was found to be superior, therefore, this explant was included for further transformation experiments. On the other hand, in spite of better transformation efficiency exhibited by DE further transformation experiments were not carried out using them as regeneration ability of this explant was found to be the lowest in case of both varieties of lentil. Thus, further transformation experiments were carried out with $\mathrm{CN}$ and CADE explants. 

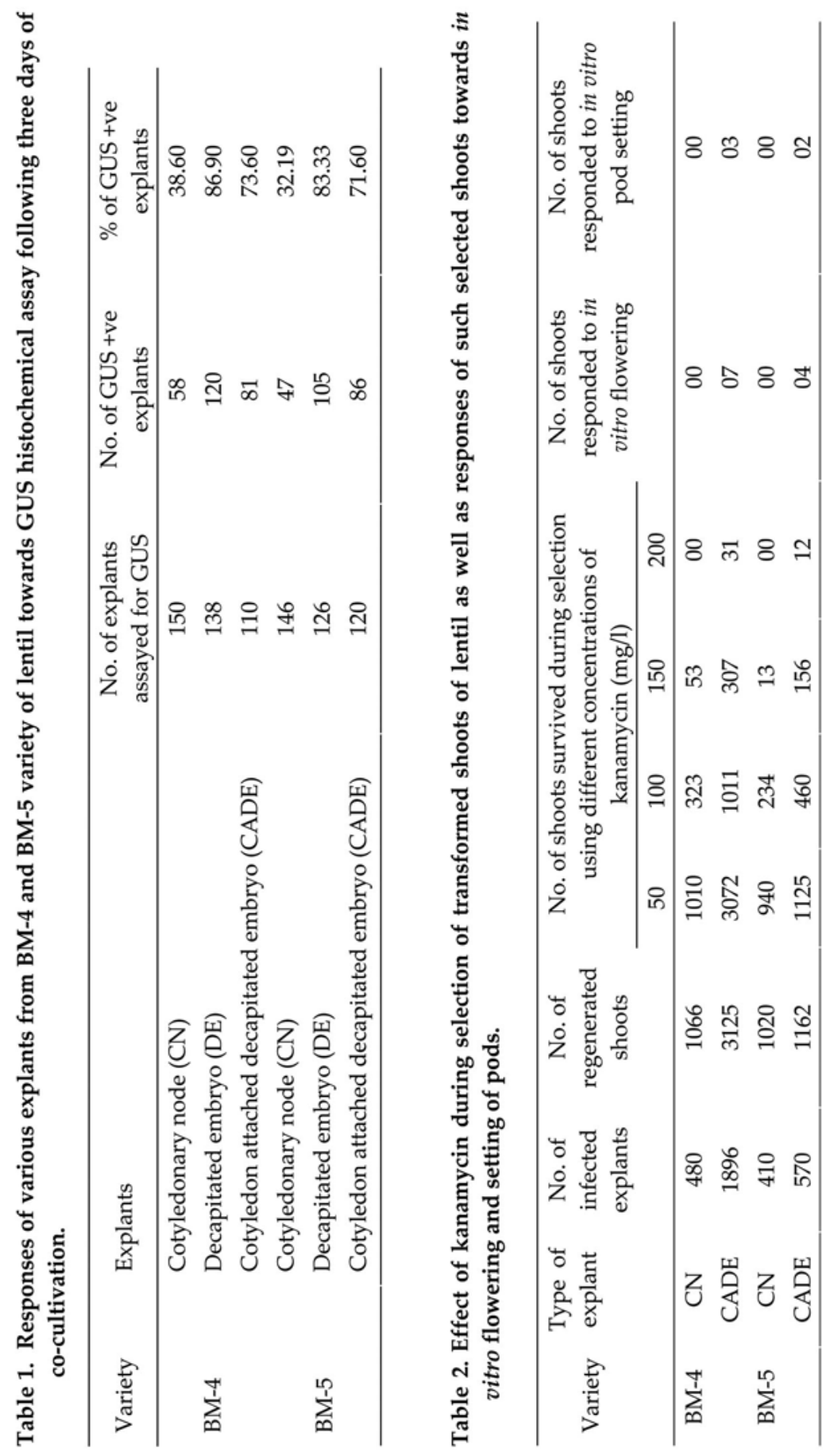
Agrobacterium-mediated genetic transformation procedure is believed to be influenced by several factors (Mansur et al. 1993). Factor that influencing successful transformation such as optical density (OD) of Agrobacterium suspensions, incubation and co-cultivation period was optimized. Bacterial suspension having an OD of 1.0 with $45 \mathrm{~min}$ of incubation and 3 days of cocultivation was found to be optimum for transformation of lentil explants.

Krishnamurthy et al. (2000) were able to obtain transgenic chickpea plants by incubating mature embryo explants for $20 \mathrm{~min}$ followed by 3 days of cocultivation. Tewari-Singh et al. (2004) obtained transformed plantlets in chickpea by employing the same co-cultivation period of 3 days but the incubation period for the explants in bacterial suspension was maintained for 1 - $2 \mathrm{hrs}$.

A good number of explants which were co-cultured with Agrobacterium strain LBA4404 showed positive to GUS staining. GUS positive regions were visualized at the peripheral area of the cut surfaces as well as within the internal tissues of various explants. Prominent blue coloured (GUS positive) zones were visualized within co-cultured explants. Stereomicroscopic view of these blue colour zones has been presented in Figs 1 and 2 .

After performing transient GUS assay the remaining explants following cocultivation were soaked with $300 \mathrm{mg} / \mathrm{l}$ ticarcillin for $15 \mathrm{~min}$ and then transferred to a previously developed regeneration medium (Sarker et al. 2003b) containing $2.22 \mu \mathrm{M}$ BAP, $2.32 \mu \mathrm{M} \mathrm{Kn}, 0.29 \mu \mathrm{M} \mathrm{GA}$, $30.35 \mu \mathrm{M}$ tyrosine with $100 \mathrm{mg} / \mathrm{l}$ ticarcillin for shoot multiplication via organogenesis. When the regenerating shoots attained a height of $2-3 \mathrm{~cm}$, the shoots were subcultured in the same media but with kanamycin for selection of transformed shoots. Initiation of multiple shoots was found to be retarded in presence of kanamycin. Therefore a preculture period and a delayed selection with kanamycin were followed in obtaining regeneration from explants with higher transformation efficiency. Similar observation during selection of transformed shoots was also reported in other plant species such as, alfalfa, chickpea, peanut and lentil (McHughen et al. 1989, Pezzoti et al. 1991, Kar et al. 1996, Sarker et al. 2003a). For this experiment, initially $50 \mathrm{mg} / \mathrm{l} \mathrm{kanamycin} \mathrm{was} \mathrm{used} \mathrm{as} \mathrm{the} \mathrm{selection} \mathrm{pressure.} \mathrm{After} 14$ days, only green and healthy shoots were subcultured in fresh medium with $100 \mathrm{mg} / \mathrm{l}$ kanamycin and $100 \mathrm{mg} / \mathrm{l}$ ticarcillin. Then the concentration of kanamycin was raised up to $150 \mathrm{mg} / \mathrm{l}$ in the third subculture and then $200 \mathrm{mg} / \mathrm{l}$ in the fourth subculture. From this experiment it was revealed that with the increase of kanamycin concentration the percentage of survived shoots were found to decrease. Due to effect of kanamycin the shoots first became albino and finally failed to survive. It was observed that all the non infected explants (negative control) died in presence of $200 \mathrm{mg} / \mathrm{l} \mathrm{kanamycin} \mathrm{within} 15$ days (Fig. 3) Therefore 
the shoots that survive in this selection medium containing $200 \mathrm{mg} / \mathrm{l} \mathrm{kanamycin}$ and remained green and healthy were considered as putative transformed shoots.

From this experiment it was observed that, none of the $\mathrm{CN}$ derived shoots were capable to continue their growth in presence of higher concentration (200 $\mathrm{mg} / \mathrm{l}$ ) of kanamycin. Whereas a few CADE derived shoots were recovered after such selection (Fig. 4). A total of 31 kanamycin resistance shoots out of 3072 explants in case of BM-4 and 12 out of 1125 explants were recovered in case of BM-5 in final selection medium (Table 2). Therefore the frequency of recovery of putative transformed shoots was about 1.009 and 1.06 in case of BM-4 and BM-5 respectively.

Sarker et al. (2003a) also used identical concentration of kanamycin as well as procedure for the recovery of transgenic shoots in case of BM-2 and BM-4 variety of lentil using decapitated embryo explants. In chickpea Kar et al. (1996) applied two concentration of kanamycin for the selection of transformed shoots ( 25 and $50 \mathrm{mg} / \mathrm{l}$ ), Eapen and George (1994) increased kanamycin concentration gradually from $50-100 \mathrm{mg} / \mathrm{l}$ in peanut in obtaining transformed plantlets.

Histochemical GUS assay (Jefferson 1987) was used to detect the expression of GUS gene in developing shoots and leaves at the time of each subculture in selection medium. Such assay demonstrated the presence of blue coloured zones on few selected shoots and leaves (Fig. 5). But it was found that, although a number of randomly selected shoots from initial selection medium showed positive response towards GUS expression, but very few of them could survive the final selection pressure. Chimeric expression of GUS gene was also observed in a number of transformed shoots during the present study. Moreover, all shoots that survived on the final selection pressure did not show positive GUS expression. A numbers of workers reported this kind of phenomenon in other crops. Ying et al. (1992) in Carthamus and Ottavani et al. (1993) in potato found expression of GUS gene only in some kanamycin resistant calli. These observations indicate that the expression of the GUS activity in the regenerated shoots was not directly correlated with kanamycin resistance. The lack of GUS expression in kanamycin resistant shoots may be due to alternation or loss of GUS gene resulted from rearrangement of the coding sequence or methylation of the gene (Battraw and Hall 1990, Ottavani et al. 1993).

From our previous experiments it was observed that the in vitro regenerated shoots of microsperma lentil varieties failed to develop effective in vitro roots even on the medium containing higher concentration of auxins (Sarker et al. 2003a). Therefore, during the present study as an alternative method the 
technique of in vitro flowering was applied in order to obtain fertile seeds from transformed shoots.
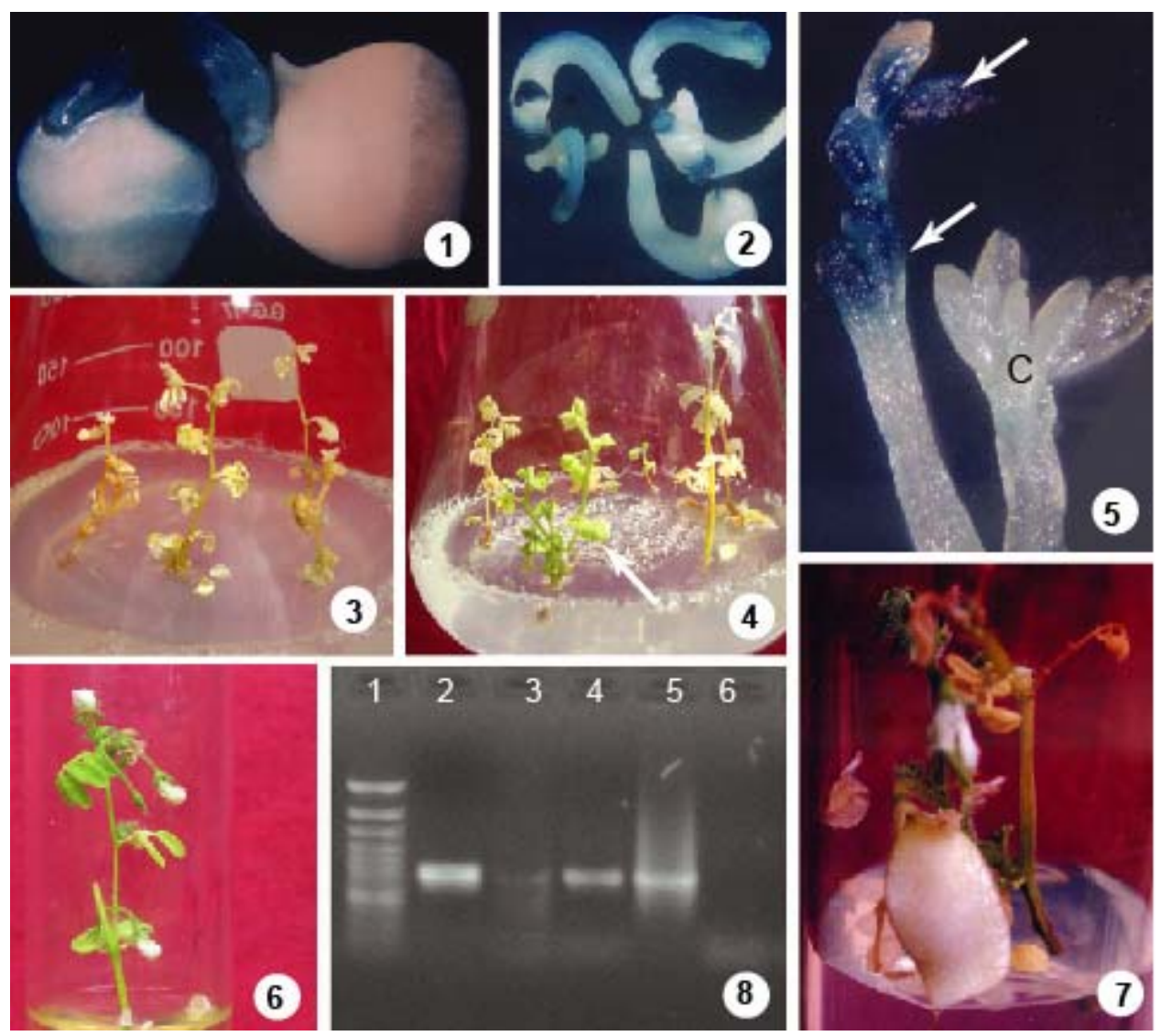

Figs 1-8: 1. Expression of GUS gene on the explants of cotyledone attached decapitated embryo from BM-4 variety showing the presence of conspicuous blue colour. 2. Same as Fig.1 but in case of decapitated embryo explants 3. Effect of kanamycin $(200 \mathrm{mg} / \mathrm{l})$ on control shoots of BM-4 regenerated from cotyledon attached decapitated embryo showing albinism. 4. Putative transformed shoots of BM-4 (arrow) survived on the selection medium containing $200 \mathrm{mg} / \mathrm{l}$ kanamycin, while non-transformed shoots failed to survive. 5. Expression of GUS gene of transformed shoots, note the presence of blue colour on the developing shoots (arrows) while the control shoots $(\mathrm{C})$ without the expression of blue colour. 6. In vitro flowers developed from the transformed shoots of BM- 4 on half strength of MS medium containing $98.4 \mu \mathrm{M}$ IBA and $2.69 \mu \mathrm{M}$ NAA and $50 \mathrm{mg} / \mathrm{l}$ kanamycin. 7. Same as Fig. 6 but showing fully developed pod. 8 . PCR amplification of GUS gene. Lane 1- ladder, lane 2-positive control, lane 3-negative control, lanes $4-5$ transformed shoots and lane 6- water control.

Under these circumstances the shoots that survived following selection were allowed to develop in vitro flowers in the flowering medium (half-strength of MS supplemented with $98.4 \mu \mathrm{M}$ IBA and $2.69 \mu \mathrm{M}$ NAA) containing $50 \mathrm{mg} / \mathrm{l}$ kanamycin. A number of experiments were carried out to select the suitable 
flowering media using MS and half-strength MS supplemented with different concentrations of IAA or IBA and NAA (data not shown). From these experiments it is revealed that half-strength MS supplemented with $98.4 \mu \mathrm{M}$ IBA and $2.69 \mu \mathrm{M}$ NAA showed the best response towards in vitro flowering and pod
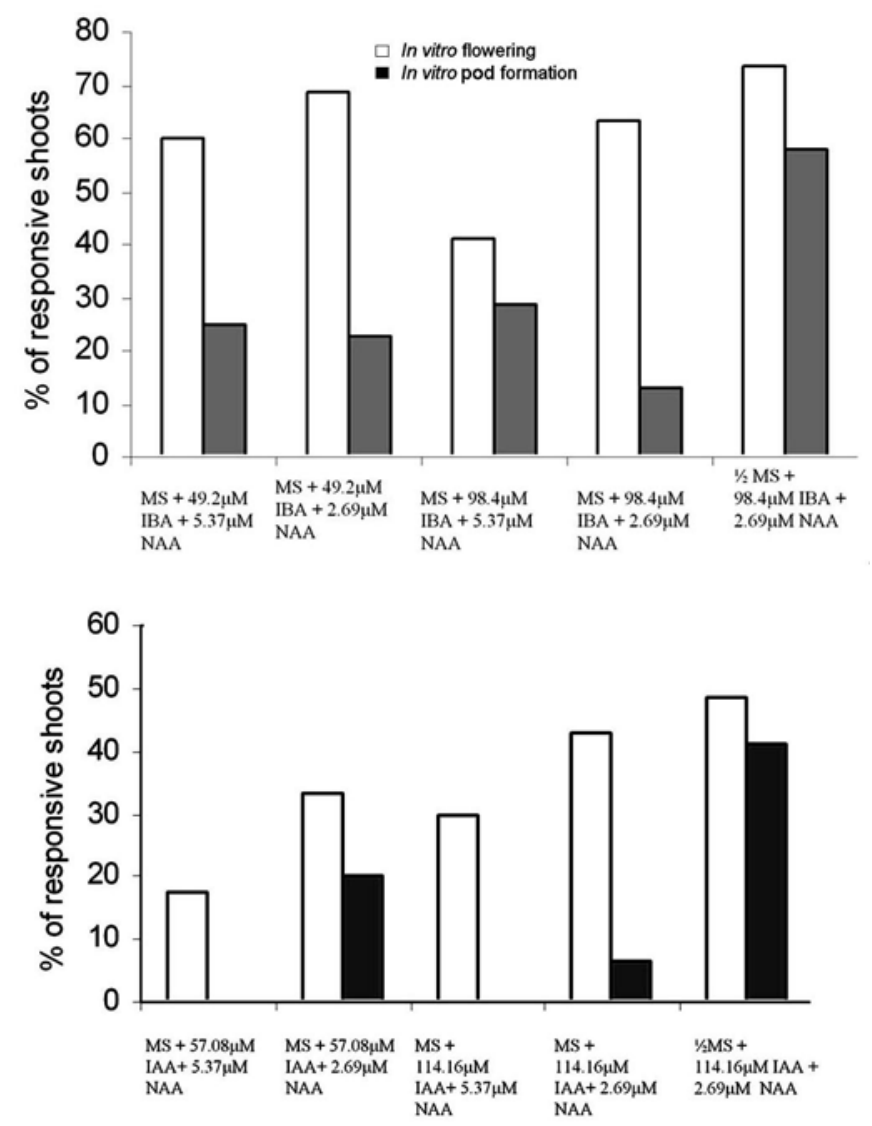

Fig. 9. Effects of various auxin supplements on in vitro flowering and pod formation in BM-4 variety of lentil.

formation (Fig. 9). It was observed that in higher concentration of kanamycin (100 mg/l) about $50 \%$ of flower bud failed to open and in $200 \mathrm{mg} / \mathrm{l}$ of kanamycin no flower bud formation was observed. For these, shoots that survived in the selection medium were separated and transferred to half-strength of MS containing $98.4 \mu \mathrm{M}$ IBA and $2.69 \mu \mathrm{M}$ NAA and $50 \mathrm{mg} / \mathrm{l}$ kanamycin. After 2 - 3 weeks in vitro flower formation was observed in the healthy shoots recovered through kanamycin selection (Fig. 6). It was found that out of 43 transformed shoots only 11 responded to flowering and the maximum number of flower per 
shoot was 3. It was also found that after 12 - 15 days 5 out of these 11 flowering shoots produced viable and healthy pods (Fig. 7) under in vitro condition.

The transgenic nature of the transformed shoots was confirmed by amplification of GUS gene present within the genomic DNA of randomly selected tranformants. Specific primers were used for this purpose as mentioned in the materials and methods. For the amplification of DNA through PCR 30 cycles were maintained. After these 30 cycles the amplified DNA was visualized through agarose gel electrophoresis. Fig. 8 is presented to show the results obtained following PCR analysis.

The development of effective rooting from in vitro derived shoots in lentil was found to be extremely difficult. Therefore development of in vitro flower and seed formation using the selected shoots was considered to be an effective method in recovering transgenic lentil plantlets. Using this protocol, future study can be conducted to transfer useful genes conferring disease, and pest resistance in microsperma varieties of lentil.

\section{Acknowledgements}

This investigation was supported by the US Department of Agriculture (USDA) through a project entitled "Improvement of grain legumes through transformation".

\section{References}

Akcay UC, Mahmoudian M, Kamci H, Yucel M and Oktem HA (2009). Agrobacterium tumefaciens- mediated genetic transformation of a recalcitrant grain legume, lentil (Lens culinaris Medik).Plant Cell Rep. 28: 407-417.

Ahmad M, Fautrier AG, McNeil DL, Hill GD and Burritt DJ (1997). In vitro propagation of lens species and their $\mathrm{F}_{1}$ interspecific hybrids. Plant Cell Tiss. Organ Cult. 47:169176.

Bajaj YPS and Dhanju MS (1979). Regeneration of plants from apical meristem tips of some legumes. Curr. Sci. 84(20):906-907.

Battraw MJ and Hall TC (1990). Histochemical analysis of CAMV 35 S promoter betaglucoronidase gene expression in transgenic rice plants.Plant Mol. Boil. 15: 527-538.

BBS (2009-2010). A pocket book of agricultural statistics. Bangladesh Bureau of Statistics, Ministry of Planning, Peoples republic of Bangladesh.

Celikkol U, Mahmoudian M, Kamci H, Yucel M and Oktem HA (2009). Agrobacterium tumefaciens-mediated genetic transformation of a recalcitrant grain legume, lentil (Lens culinaris Medik.). Plant Cell Reports 28: 407-417.

Doyle JJ and Doyle JL (1990) Isolation of plant DNA from fresh tissue. Focus 12: 13-15.

Duranti M and Gius C (1997). Legume seeds: protein content and nutritional value. Field crops Res. 53: 31-45. 
Eapen S and Goerge L (1994). Agrobacterium tumefaciens mediated gene transfer in peanut (Arachis hypogea L.) Plant cell. Rep.13: 582-686.

Fontana GS, Santini L, Caretto S, Frugis G and Mariotti D (1993). Genetic transformation in the grain legume of Cicer arietinum L. Plant cell Rep. 21: 194-198.

Gardner RC (1993). Gene transformation into tropical and subtropical crops. Scientia Hort. 55: 65-82.

Gowda CL and Kaul AK (1982). Pulses in Bangladesh. Joint publication of Bangladesh Agric. Res. Inst. and FAO.

Gould JH and Smith RH (1999). A non-distructive assay of GUS in the media of plant tissue cultures. Plant Molecular Biology Rep. 7: 209-216.

Gulati A, Schryer P and McHughen A (2001). Regeneration and micrografting of lentil shoots. In Vitro Cell. and Dev. Biol.-Plant. 37(6): 798-802.

Gulati A, Schryer P and McHughen A (2002). Production of fertile transgenic lentil (Lens culinaris Medik.) plants using particle bombardment. In vitro Cell. Dev. Boil. Plant. 38:316-324.

Hassan F, Hoque MI, Kiesecker H and Jacobsen H (2007). Transient Gus Expression in decapitated lentil embryos. Plant Tissue Cult. \& Biotech. 17(1): 97-102.

Herrera-Estrella L, Depicker A, Van Montagu M and Schell J (1983) Expression of chimeric genes transferred into plant cells using a Ti-plasmid derived vector. Nature 303: 209.

Hinchee MAW, Connor-Ward DV, Newell CA, McDonell RE, Sato SJ, Gasser CS, Fischhoff DA, Re DR, Fraley RT and Horsch RB (1988). Production of transgenic soyabean plants using Agrobacterium-mediated DNA transfer. Biotechnology 6: 915922.

Hooykaas PJJ (1988) Agrobacterium molecular genetics. Plant Molecular Biology Manual 4: 1-13.

Jefferson RA, Kavanagh TA and Bevan MW (1987). GUS fusion: Beta-glucoronidase as a sensitive and versatile gene fusion marker in higher plants. EMBO J. 6: 3901-3907.

Kar S, Johanson TM, Nayak P and Sen SK (1996). Efficient transgenic plant regeneration through Agrobacterium-mediated transformation of chickpea. Plant Cell. Rep. 16: 32-37.

Khanam R, Sarker RH, Hoque MI and Haque MM (1995). In vitro root morphogenesis in lentil (Lens culinaris Medik) Plant Tissue Cult. 5: 35-41.

Krishnamurthy KV, Suhasini K, Sagare AP, Meixner M, De Kathen A, Pickardt T and Schieder O (2000). Agrobacterium-mediated genetic transformation of chickpea (Cicer arietinum L.) embryo axes. Plant Cell. Rep. 19: 235-240.

Larquin PF, Cai Z, Stiff CM and Fuerst EP (1998). Half embryo co-cultivation technique for estimating the susceptibility of pea (Pisum sativum L.) and lentil (Lens culinaris Medik.) cultivars to Agrobacterium tumefaciens. Mol. Biotechnol. 9:175-179.

Malik KA and Saxena PK (1992). Thiadiazuron induces high frequency shoot regeneration in intact seedlings of pea (Pisum sativum L.), chickpea (Cicer arietinum). lentil (Lens culinaris). Aust. J. Plant physiol. 19: 731-740. 
Mandal AP, Maiti A and Elanchezhian R (2000). In vitro flowering in maize (Zea mays L.) Asia Pacific Journal of Molecular Biology and Biotechnology. 8: 81-83.

Moss GI (1969). Influence of temperature and photoperiod of flower induction and inflorescence development in sweet orange (Citrus sinensis L. Osbeck). Journal of Horticultural Science. 44: 311-320.

Mansur EA, Lacortee C, DeFreitus VG, DeOliviera DE, Timmerman B and Cordeiro AR (1993). Regulation of transformation efficiency of peanut (Arachis hypogea L.) explants by Agrobacterium tumefaciens. Plant Sci. 89: 93-99.

McHughen A, Jordan M and Feist G (1989). A preculture period prior to Agrobacterium inoculation increases production of transgenic plants. J. Plant. Physiol. 135: 245-248.

McKently AH, Moore GA, Doostdar H and Niedz RP (1995). Agrobacterium-mediated genetic transformation of peanut (Arachis hypogea L.) embryo axes and the development of transgenic plants. Plant Cell Rep. 14: 699-703.

Meurer CA, Dinkins RD and Collins GB (1998). Factors affecting soyabean cotyledonary node transformation. Plant Cell Rep. 18: 180-186.

Nadgauda RS, Parasharami VA and Mascarenhas AF (1990). Precocious flowering and seedling behaviour in tissue-cultured Bamboos. Nature 344: 335-336.

Neelam S, Setia R.C, Kaur D and Malik CP (1988). Effect of Mixatalol on the flowering and pod set patterns, yield components and seed quality of lentil. Lens Newsletter. 15(2):18-21.

Ottaviani MP, Smits T and Hanish CH (1993). Differential methylation and expression of the $\beta$-glucuronidase and neomycin phosphotransferase genes in transgenic plants of potato cv. Bintje Plant Sci. 88: 73-81.

Pezzoti M, Pupilli F, Damiani F and Arcioni S (1991). Transformation of Medicago sativa L. using a Ti-plasmid derived vector. Plant Breed. 106: 39-46.

Polanco MC, Pelaez MI and Ruiz ML (1988). Factor affecting callus and shoot formation from in vitro cultures of Lens culinaris Medik. Plant Cell, Tissue and Organ Cult. 15(2): 175-182.

Sarker RH, Mustafa BM, Biswas A, Mahbub S and Hoque MI (2003a). Agrobacterium mediated transformation of lentil (Lens culinaris Medik.). Plant Tissue Cult. 13(1): 1-12.

Sarker RH, Mustafa BM, Biswas A, Mahbub S, Nahar M, Hashem R and Hoque MI (2003b). In vitro regeneration in lentil (Lens culinaris Medik.). Plant Tissue Cult. 13(2): 155-163.

Singh RK and Raghubangshi SS (1989). Plantlet regeneration from nodal segment and shoot tip derived explant of lentil. Lens Newsletter. 16(1): 33-35.

Sheeja TE, Mandal BA (2003). In vitro flowering and fruiting in tomato (Lycopersicon esculentum Mill.). Asia pacific journal of Molecular Biology and Biotechnology. 11(1): 37-42.

Singh M, Jaiswal U and Jaiswal VS (2000). Thidiazuron induced in vitro flowering in Dendroclamus strictus Nees. Current Science. 79: 1529-1530.

Tavallaie FZ, Ghareyazie B, Bagheri A and Sharma KK (2011). Lentil regeneration from cotyledon explant bearing a small part of embryo axis. Plant Tissue Cult. and Biotech. 21(2): 169-180. 
Tewari-Singh N, Sen J, Kiesecker H, Reddy VS, Jacobson HJ and Guha Mukherjee S (2004). Use a herbicide or lysine plus threonine for non antibiotic selection of transgenic chickpea. Plant Cell Rep. 22: 576-583.

Vandana AK, Kumar A and Kumar, J (1995). In vitro flowering and pod formation in cauliflwer ( B. oleracea var. botrytis). Current Science 69: 25.

Warkentin TD and McHughen A (1991). Crown gall formation of lentil (Lens culinaris Medik.) with virulent strains of Agrobacterium tumefaciens. Plant Cell Rep. 10: 489-493.

Warkentin TD and McHughen A (1992). Agrobacterium tumefaciens-mediated betaglucoronidase (GUS) gene expression in lentil (Lens culinaris Medik.) tissues. Plant Cell Rep. 11: 274-278.

Warkentin TD and McHughen A (1993). Regeneration from lentil cotyledonary nodes and potential of this explant for transformation by Agrobacterium tumefaciens. Lens Newsletter. 20(1): 26-28.

Ying M, Dyer WEB and Gergman IW (1992). Agrobacterium tumefaciens-mediated transformation of safflower (Carthamus tinctorius L.) cv. 'Centennial' Plant Cell reports. 11: 581-585. 